\title{
THE IMPACT OF MEDIATION PRACTICE ON AND THE RESOLUTION OF GRIEVANCES, THE PRESERVATION OF EMPLOYMENT RELATIONSHIPS AND TERMINATION
}

\author{
Andrew Agapiou*
}

\begin{abstract}
"While many (employment disputes) are resolved informally, an increasing number progress into external resolution procedures such as mediation. While these procedures seek to resolve grievances and preserve employment relationships, many end with termination" (Walker and Hamilton, 2015). This paper explores how mediation practice might be affected by each of the three purposes outlined above: resolution of grievances, preservation of employment relationships and termination? The paper also draws upon the literature on employment mediation to consider the ethical and practical consequences of these distinct goals.
\end{abstract}

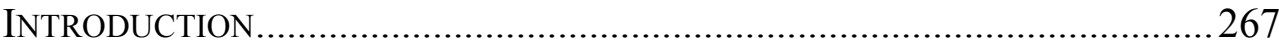

I. The Modern Dispute Resolution ContinuUM .................................268

A. Important Qualifications .................................................. 268

B. Employment Mediation Principles ................................... 270

II. Mediation Ethics AND PRACTICE ................................................... 270

A. Grievance Resolution....................................................... 271

B. Relationship Preservation ............................................... 272

C. Termination ................................................................... 274

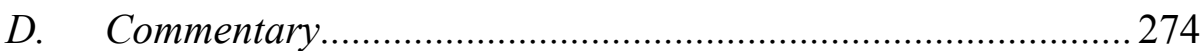

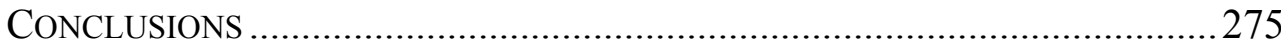

\section{INTRODUCTION}

The 2015 Walker and Hamilton observations concerning relationships observed between New Zealand "external employment resolution processes" and termination outcomes, provides the platform for this critical discussion. ${ }^{1}$ On an initial consideration, employment (workplace) grievance resolution, employment relationship preservation and termination each invite distinct mediation ethics and practice approaches. ${ }^{2}$ The relevant

\footnotetext{
* Dr Andrew Agapiou, Senior Lecturer, Department of Architecture, Strathclyde University, Level 3 , James Weir Building, 75 Montrose street, Glasgow G1 1XJ. Research fields: Alternative Dispute Resolution, Arbitration, Adjudication, Mediation.

${ }^{1}$ Bernard Walker, \& R. T. Hamilton, What Influences the Progression of Employment Disputes?, INDUSTRIAL RELATIONS JOURNAL 117, 130 (2015).

${ }^{2}$ Roger Fisher, \& William Ury, Getting to Yes: Negotiating an Agreement without Giving in, 4-8 (3rd ed., Random Business 2012).
} 
literature examined here confirms this initial view acquires a different character on a more detailed exploration.

Key external employment resolution processes, as understood in modern Alternative Dispute Resolution (ADR) dynamics are identified and explained in Part One. ${ }^{3}$ Ethical and practical consequences are given detailed Part Two evaluation. The collective Parts One and Two discussion threads contribute to the Part Three conclusion that, whilst the Walker and Hamilton title statement may be generally correct, mediated disputes are not as likely to yield such outcomes.

\section{The Modern Dispute Resolution CONTINUUM}

\section{A. Important Qualifications}

Three qualifications give the Walker and Hamilton statement its fuller understanding. The first is identifying the primary employment dispute resolution methods in addition to mediation. These are a continuum defined by the relative degrees of formality and conclusiveness encouraged by each resolution option. ${ }^{4}$ As Walker and Hamilton suggest, many employmentrelated disputes are resolved informally. ${ }^{5}$ Negotiation is the dispute resolution continuum commencement point, where parties (either privately, or through an intermediary), settle their contentious issue(s). ${ }^{6}$ Binding, compulsory arbitration is at the opposite end of this procedural ADR spectrum. Only conventional civil litigation exceeds it in terms of formality and conclusive effects. ${ }^{7}$

In this continuum, mediation occupies a broad middle ground. It tends to be less structured that, any negotiations, but by any definition, mediation is non-binding. ${ }^{8}$ A second title statement qualification flows from the first. Mediation has four variants, each possessing features suitable to specific

\footnotetext{
${ }^{3}$ Simon Roberts, \& Michael Palmer, Dispute Processes, ADR and the Primary Forms of DecisionMaking, 174 (CUP 2005); see also Brian Doyle, Alternative Dispute Resolution: The Employment Tribunal, 81(1) ARBITRATION 20-21 (2015).

${ }^{4}$ Charlotte Sweeney, Mediation and the Workplace, 39 EQuAl OPPORTUNITIES REviEW 8 (2013); see also Emma Callahan, Stepping into another Man's Shoes-the Need for Mediation in the Workplace: the Neutral Broker-the Importance of Mediation in the Workplace, 7 EMPLOYMENT LAW REVIEW-IRELAND 9 (2007).

${ }^{5}$ Walker, \& Hamilton, (n 1), 118.

${ }^{6} \mathrm{Ibid}$, see also Steven Pearl, A Critique of "Getting to Yes", Mediation and Negotiation Blog 1 (2013).

${ }^{7}$ As reinforced in Civil Procedure Rules 1998 (CPR 1998) Practice Direction "Pre Action Conduct and Protocols" (2015) [3], [6].

${ }^{8}$ John Wade, Evaluative and Directive Mediation: All Mediators Give Advice-Part 1 of 2, Mediate.COM 1 (2011).
} 
dispute circumstances. The mediator might simply encourage the parties to tell their respective stories (narrative mediation). ${ }^{9}$ Alternatively, the mediator may assume a discussion facilitator role, where the mediator offers no personal opinions concerning how their dispute might be resolved. ${ }^{10}$ The third variant permits the mediator to evaluate the respective positions, and provide input concerning settlement. ${ }^{11}$

The fourth mediation approach is assertive, as the parties acknowledge this subject matter expert mediator will direct them towards settlement. ${ }^{12}$ This directive mediation is often premised on the mediator's 'what if' scenario, based on the mediator's suggested likely outcomes after arbitration or litigation. ${ }^{13}$ In this variant, the mediator proactively identifies the dispute issues, and seeks ways to find common ground. ${ }^{14}$

The third Walker and Hamilton observation qualification is based on their New Zealand-centred study. The title statement is based on these authors' New Zealand mediation procedures observation, where by national law employment relationships must be preserved wherever possible. ${ }^{15}$ The legislation states: (i) employment relationship problems should be resolved promptly, including utilising expert problem-solving assistance; ${ }^{16}$ (ii) flexible problem-solving procedures ${ }^{17}$ and (iii) mediator 'actively procedural management'. ${ }^{18}$ This progressive legislation is not the global employment relations standard. ${ }^{19}$ The traditional UK aversion to mandatory mediation is captured by Genn: "... Mediation may be about problemsolving, ... compromise ... repairing damaged relationships [but not] substantive justice'. ${ }^{20}$ One might argue that, unless a comparative jurisdiction has similar legislation, the Walker and Hamilton findings are less compelling. $^{21}$

\footnotetext{
${ }^{9}$ Erich Suter, Conflict Resolution and Mediation within the Workplace, 78(1) ARBITRATION 37, 39. (2012)

${ }^{10}$ Marvin Johnstone, The Integrity of ADR Processes and the Risks of Blurred Boundaries, MEDiATE.COM 1 (2015).

${ }^{11}$ Ibid.

${ }^{12}$ Wade, (n 8).

${ }^{13}$ Ibid.

${ }^{14}$ A point taken from Anthony Stitt, Alternative Dispute Resolution for Organizations: How to Design a System for Effective Conflict Resolution, 77-79 (John Wiley \& Sons 2008).

${ }^{15}$ Walker, \& Hamilton, (n 1), 114; see also Employment Relations Act 2000 (ERA 2000) (NZ), s. 143.

${ }^{16}$ ERA 2000 s. 143 (c).

${ }^{17}$ Ibid, s. 143 (d).

${ }^{18} \mathrm{Ibid}$, s. 143 (e).

${ }^{19}$ See Klaus J. Hopt, \& Felix Steffek, Mediation: Principles and Regulation in Comparative Perspective (OUP 2012), Part II and Part III, suggesting NZ's ERA 2000 provisions are an international exception.

${ }^{20}$ Hazel Genn, Judging Civil Justice 117-118 (OUP 2009).

${ }^{21}$ The researcher's opinion, based on Walker/Hamilton study results.
} 


\section{B. Employment Mediation Principles}

The proposition that differing ethics and practical considerations may arise depending on which employment dispute ADR option is utilised is undoubted. The following universally accepted core mediation principles frame the following discussions. Every mediation must be: (i) confidential; (ii) non-binding; (iii) all information exchanged during mediation is inadmissible in subsequent proceedings ${ }^{22}$ and (iv) the process is terminable at any point by either party. ${ }^{23}$ These principles contribute to mediation's reputation as a cost-effective employment dispute resolution mechanism. ${ }^{24}$ Employment mediation, with its interests versus position orientation, is more often equated with positive mutual outcome objectives, and not employment termination. ${ }^{25}$ The sole exceptions are situations where employee termination is either expressly predicted, or an implicit issue between the parties. ${ }^{26}$

\section{Mediation Ethics AND PRACTICE}

Three employment dispute outcomes potentially generated by mediation (grievance resolution, relationship preservation and termination) are now evaluated. The applicable mediation ethics framework is largely subsumed within the Part One core principles. ${ }^{27}$ Mediator good faith is the overarching notion that essentially binds these principles. Every mediation demands mediator honesty and fair-mindedness. 'Rogue mediators' are beyond this discussion. ${ }^{28}$

An intriguing good faith issue arises when the mediator is confronted by an unwilling participant. ${ }^{29} \mathrm{~A}$ 'sham' mediation is dishonest to its sincere participant; terminating mediation might defeat any future efforts resolution

\footnotetext{
${ }^{22}$ Goh Yihan, A Wrong Turn in History: Re-understanding the Exclusionary Rule against Prior Negotiations in Contractual Interpretation, 5 J.B.L. 36 (2104); see also Farm Assist Ltd v. SS EWHC 1102 (TCC), 30, 31 (2009), re mediation privilege.

${ }^{23}$ Ibid.

${ }^{24}$ Walker, \& Hamilton (n 1), 117-118, citing Rodger Ridley-Duff, \& Anthony Bennett, Towards Mediation: Developing a Theoretical Framework to Understand Alternative Dispute Resolution, 42 INDUSTRIAL RELATIONS JOURNAL 2, 106 (2011).

${ }^{25}$ See ACAS (Advisory, Conciliation AND ARbitration SERviCe), Discipline and GrievanCe At WORK (2009).

${ }^{26}$ The researcher's opinion, based on reading (i) ACAS (Advisory, Conciliation and Arbitration Service) (2015b) Communications and Consultations, and ACAS (n 25).

${ }^{27} \mathrm{See}$ (n 22)-(n 26).

${ }^{28}$ E.g. mediators with no "hidden agenda".

${ }^{29}$ Potential later costs consequences, where a judge determines mediation was not sincerely utilised: Orange v. Hoare, EWHC 223 (2008); Halsey v. Milton Keynes, EWCA Civ 576, [22] (2004).
} 
efforts. ${ }^{30}$ These points provide further background against which the three dispute resolution objectives are now examined.

\section{A. Grievance Resolution}

'Everyday' grievance resolution is highlighted here. This adjective does not diminish the particular dispute importance, so much as it underscores that, if every workplace conflict was arbitrated or litigated, entire legal systems might collapse under such claims' collective weight. ${ }^{31}$ The distinction made between grievances and disciplinary issues is important in this context. Grievances are less serious employee concerns, problems or workplace complaints raised with the employer ${ }^{32}$ Disciplinary matters are ones based on employer concerns related to employee work quality, workplace conduct or absences. ${ }^{33}$

Doyle explains how prevailing England and Wales employment tribunal rules governing workplace dispute resolution afford excellent guidance regarding external mediation importance. ${ }^{34}$ The overriding Employment Tribunal (ET) rules objective is 'fair and just' claims resolution. These ET procedures mirror an effective mediation process: (i) ensuring an equal footing for both parties; (ii) resolution procedures proportionate to dispute issue(s) importance; (iii) avoid unnecessary formality, encourage flexibility, avoid delay and save expense. ${ }^{35}$

In these 'everyday' grievance circumstances, predicting ultimate outcomes may be difficult. Suter notes from UK workplace studies that, approximately 60 per cent of these disputes involve co-workers allegedly not carrying their fair workload share, personalities, contrasting work ethics and goal conflict. ${ }^{36}$

In these instances, mediation constructed on core ethics principles, whilst accounting for Doyle's suggested practical criteria often succeeds in bringing the disputants closer together. ${ }^{37}$ Greater workplace harmony is an overarching mediation objective. ${ }^{38}$ The convergence of mediation ethics, practical approaches and effective resolution in this 'everyday' grievance

\footnotetext{
${ }^{30}$ See Yihan, (n 22).

${ }^{31}$ See ACAS, (n 26).

${ }^{32}$ UK GOVERnMENT, SOlving A WorkPlace Dispute 1 (2015).

${ }^{33} \mathrm{Ibid}$.

${ }^{34}$ Doyle (n 3), footnote 3.

${ }^{35}$ Ibid.

${ }^{36}$ Ibid.

${ }^{37}$ See Wade (n 8), and Stitt (n 14).

${ }^{38}$ Charlie Irvine, Do You See What I'm Dealing with Here? Vicious Circles in Workplace Conflict, 118(Dec) EMP. L.B. 6-7 (2013).
} 
sphere is rooted in the Part One position versus interest distinction. ${ }^{39}$ Irrespective of which Part One mediation variant is adopted, a desirable outcome is far more likely where the parties' underlying interests are understood, and rigid negotiating position barriers are overcome. ${ }^{40}$

Fisher and Ury promoted the positions versus interests dichotomy as essential to every dispute resolution effort. ${ }^{41}$ It is arguably even more essential in lower level, employment grievance mediation. ${ }^{42}$ Successful mediator separation of the participants from their positions reduces the risk that, the opposite party's responses will be interpreted as personal attacks. ${ }^{43}$ Parties are encouraged to address the issues without destroying their ongoing relationship. ${ }^{44}$

\section{B. Relationship Preservation}

Ethics and practical issues are more complicated where relationship preservation is the dispute resolution objective. As the Section 1 discussions suggest, grievance mediations will invariably include a relationship preservation element. ${ }^{45}$ When the dispute involves issues that may bring the employment relationship to an end, the mediator must be alive to the risk that even-handed mediation is not co-opted, and the employer uses the process to achieve an unethical end (such as essentially encouraging the employee to leave their enterprise). ${ }^{46}$

As discussed in the Part One Walker and Hamilton statement qualifications, ${ }^{47}$ the New Zealand legislative requirement that, employment dispute resolution must be conducted with employment relationship preservation as its objective is not universally adopted. ${ }^{48}$ However, the ERA 2000 provisions these authors discuss are highly relevant as general mediator ethics and practical guidance here. The enumerated ERA 2000 mediation objectives are a sound basis on which any relationship preservation efforts can safely proceed. ${ }^{49}$

\footnotetext{
${ }^{39}$ Fisher and Ury, (n 2), 11.

${ }^{40}$ Ibid.

${ }^{41}$ Ibid.

${ }^{42} \mathrm{Ibid}$, and Irvine (n 38), 7.

${ }^{43}$ Stephen Ruttle, Mediation: A Social Antibody?, 79(3) Arbitration 295, 300 (2013).

${ }^{44}$ Fisher and Ury, (n 2), 11, 12.

${ }^{45}$ Part One, (n 7).

${ }^{46}$ See also Chantal Mak, The Lion, the Fox and the Workplace: Fundamental Rights and the Politics of Long-Term Contractual Relationships, CENTRE FOR THE STUDY OF EUROPEAN CONTRACT LAw 8 (2009).

${ }^{47}$ Part One (n 4), onwards.

${ }^{48}$ Walker, \& Hamilton (n 1), 117, 121.

${ }^{49}$ The researcher's opinion, based on reading ERA 2000 s. 143, and Part One sources.
} 
The mediation must be conducted with the same ethical care and costeffective practical orientation as a grievance-based proceeding, with this one further requirement as dictated by the type of mediation the parties have engaged. Of the four Part One mediation variants (narrative, facilitative, evaluative and directive) ${ }^{50}$ directive mediation plainly poses the greatest ethical and practical challenges for the mediator. This person has been presumptively nominated by the parties on the basis of their proven subject matter expertise, experience and mediation competence. ${ }^{51}$ To maintain essential mediator fairness, honesty, and encouraging appropriate interests versus position considerations, this expert must resist the temptation to dictate terms, as opposed to rational persuasion of the parties to move towards the mediator's suggested resolution. ${ }^{52}$

As Yu's analysis confirms, there is the related risk in this mediation dynamic that forceful, but even-handed directive mediation will descend into a 'carrot and stick' procedure, where the mediator crosses the boundary from impartial, settlement-motivated expert to psychological bully. ${ }^{53}$ The psychology behind such ethical transgressions is readily understood. In a directive mediation, the mediator has arguably greater responsibility to take three essential preventative ethics measures: (i) to ensure the mediator has not rushed to judgment, (ii) pre-judged the dispute, or (iii) in any way encouraged the perception that the mediation must result in a mediatorspecified outcome. $^{54}$

In this important respect, the mediator must avoid the risk of using his or her expertise that the parties have retained, to create a power imbalance that destroys the mediation fairness, and party-centred settlement objectives. Dolder makes this point attractively in a 2004 Article that retains its persuasive power. ${ }^{55}$ Mediation is intended to empower its participants, where the parties' autonomous mediation participation encourages full and frank information exchanges that ultimately promote settlements. Dolder questions whether self-determination truly exists if ' $\ldots$ so-called 'neutral' ... use a variety of 'magical' tools to direct parties towards settlement outcomes, [when] disputants are unaware of the deception

\footnotetext{
${ }^{50}$ See (n 10)-(n 14).

${ }^{51}$ Derek Roebuck, Keeping an Eye on Fundamentals, 78(4) ARB. 375-376 (2012).

${ }^{52}$ Andrew Boon, Peter Urwin and Valeriya Karuk, 'What difference does it make? Facilitative judicial mediation of discrimination cases in employment tribunals' (2011) 40(1) I.L.J. 45, 47.

${ }^{53}$ Hong-Lin Yu, Carrot and Stick Approach in English Mediation-There Must be another Way, 8(1) CONTEMPORARY ASIA ARBITRATION JOURNAL 81, 84 (2015).

${ }^{54}$ Boon, et al. (n 52).

${ }^{55}$ Cheryl Dolder, The Contribution of Mediation to Workplace Justice, 33(4) I.L.J. 320 (2004).
} 
involved? ${ }^{, 56}$

\section{Termination}

Just as ADR options move along their Part One continuum, and mediation variants are similarly analogised, employment termination mediations arguably encompass the greatest ethical and practical dispute resolution challenges. ${ }^{57}$ This reason is straightforward-the stakes for each party are the highest, given termination is the most serious workplace dispute outcome for any employee ${ }^{58}$ Where the mediator does not strive relentlessly to ensure that, all Part One ethical obligations are observed, there is little doubt that, the Walker and Hamilton study findings might be borne out-mediation is essentially subverted into a negotiated employment termination.

The mediator's approach to these disputes is similar to those required in grievance and relationship preservation cases, with the only different being the frequency with which the mediator must reassess how the mediation is proceeding. ${ }^{59}$ In other words, the termination dispute mediator must be constantly on their guard that, all ethical requirements are being satisfied. Conversely, where required the mediator must recalibrate the ongoing process, or otherwise continually remind the participants that irrespective of the outcome, the parties will ideally secure a resolution that, they accept as 'theirs', and not one externally imposed upon them. Halsey affirms the proposition that, mediating parties are permitted to adopt any position they wish in the mediation. ${ }^{60}$ Mediation ethics and practical constraints do not change across the grievance, relationship preservation and termination disputes spectrum, so much as the mediator obligations become more difficult to discharge. ${ }^{61}$

\section{Commentary}

Bennett strikes a far more optimist note regarding workplace dispute mediation than do Walker and Hamilton. ${ }^{62}$ Citing recent research promoting

\footnotetext{
${ }^{56}$ Ibid, at 333 .

${ }^{57}$ A point taken from Richard Kay, Employment Mediations, 112(16) L.S.G. 17 (2015).

${ }^{58}$ Walker, \& Hamilton, (n 1).

${ }^{59}$ John Mason, How Might the Adversarial Imperative be Electively Tempered in Mediation?, 15(1) LEGAL ETHICS 111, 113-115 (2012).

${ }^{60}$ Halsey, (n 29) (ii), [14].

${ }^{61}$ Boon, et al. (n 52).

${ }^{62}$ Anthony Bennett, The Role of Mediation: A Critical Analysis of the Changing Nature of Dispute Resolution in the Workplace, 41(4) I.L.J. 479, 484 (2012).
} 
mediation as the primary workplace conflict management tool, Bennett contends that, where disputes involve relationship issues, mediation is a highly desirable alternative to traditional adversarial options. ${ }^{63} \mathrm{He}$ also endorses mediation as offering greater procedural control over its outcomes to disputants. ${ }^{64}$ When these Bennett observations are factored into the larger Part Two discussions, it is apparent that, the identified Walker and Hamilton risks that, employment mediation will too often result in termination are more likely overcome, so long as the mediator never loses sight of the need to maintain ethical vigilance and even-handed, transparent procedural control. ${ }^{65}$

\section{CONCLUSIONS}

The various discussion threads developed in Parts One and Two are readily fashioned into the following two-pronged conclusion. The first is that, the risk Walker and Hamilton identify (many employment mediations can result in often undesirable termination outcomes) is real. Mediators must be constantly on guard that, fundamental mediation ethics and practical considerations are properly aligned. The parties must be encouraged to make the proceedings their own, where common ground is gained and fair, balanced resolution prospects are correspondingly increased.

The second conclusion, links the Walker and Hamilton study qualifications highlighted in Part One to the noted Part Two Section 4 commentaries. Mediators assume a challenging task in any employment dispute scenario where the parties' emotions or entrenched positions are resolution barriers. Where the mediator takes care to ensure fairness, good faith, civility and even-handedness are the obvious mediation features, the termination outcome risks identified by Walker and Hamilton will inevitably be reduced.

\footnotetext{
${ }^{63} \mathrm{Ibid}$.

${ }^{64} \mathrm{Ibid}$.

${ }^{65}$ As suggested from reading Bennett, (n 62).
} 